\title{
ROLE OF LOCAL INFILTRATION OF INJECTION BUPIVACAINE IN REDUCING EARLY POST-OPERATIVE PAIN
}

\author{
Mudassar Jabeen ${ }^{\mathrm{a}}$, Fawad Zafar ${ }^{\mathrm{b}}$, Sumara Tabassam ${ }^{\mathrm{C}}$, Farhad Alam ${ }^{\mathrm{d}}$, Muhammad Sohail \\ assistant Professor, General Surgery, Independent University Hospital, Faisalabad. \\ ${ }^{\text {b} P o s t ~ G r a d u a t e ~ R e s i d e n t, ~ G o v e r n m e n t ~ G e n e r a l ~ H o s p i t a l, ~ S a m a n a b a d ~ F a i s a l a b a d . ~}$ \\ 'Assistant Professor, Anesthesia, Madinah Teaching Hospital Faisalabad. \\ d Senior Registrar, Children Hospital Faisalabad. \\ eAssistant Professor, Urology, Madinah Teaching Hospital Faisalabad.
}

\begin{abstract}
:
BACKGROUND \& OBJECTIVE: Intolerable morbidity occurs after major thoracic, orthopedic or abdominal surgeries due to post-operative pain. Inadequately controlled pain leads to patient displeasure and major morbidities like post-operative pulmonary dysfunctions and cardiac ischemic changes. Various techniques are presently used to treat this pain and opiods are the most regularly used medications by parenteral or neuraxial route. Intolerable morbidity occurs postoperatively due to inadequately controlled pain. The objective of this study was to compare the mean pain scores in patients undergoing laparotomy with and without local infiltration of injection bupivacaine at surgical incision site in post-operative period.

METHODOLOGY: This randomized controlled trial was conducted at surgical department Allied hospital Faisalabad from June 2017 to December 2017. Total 80 patient were included in this study that were randomly divided into two groups using random number tables. In post-operative period, patients of both groups were given treatment as per requirement of their respective diseases. They received a baseline analgesia using Inj. Toradol (ketorolac) 30mg/1ml intravenously every 8 hours, first dose given during the surgery. The study group was additionally given $10 \mathrm{ml}$ Inj. Bupivacaine $\mathrm{HCl} 0.5 \%$ diluted with $10 \mathrm{ml}$ saline injected into the subcutaneous plane around the incision immediately after the closure of skin and time was noted. No further difference in the treatment of patients of both groups required for the purpose of this study. The patients in both groups were compared for the degree of pain experienced by them in early post-operative period. This information was collected using Numeric pain scale, 10 being worst pain and 1 meaning least appreciable pain. These assessments were done 2 and 4 hours after surgery.

RESULTS: We recorded pain score $3.0 \pm 0.75$ in study and $5.2 \pm 0.72$ in control group, P-value was $<0.001$ showing a significant difference.

CONCLUSION: We concluded that there is significantly lower pain in patients infiltrated with injection bupivacaine around surgical incision in early post-operative period as compared to those who had only intravenous analgesics.

KEYWORDS: Laparotomy, Local infiltration of injection bupivacaine, Mean post-operative score.
\end{abstract}

How to cite this:

doi: https://doi.org/10.37723/jumdc.v11i1.306

Jabeen M, Zafar F, Tabassam S, Alam F, Sohail M. ROLE OF LOCAL INFILTRATION OF INJECTION BUPIVACAINE IN REDUCING EARLY POST-OPERATIVE PAIN. jumdc. 2020;11(1):1-8.

doi: https://doi.org/10.37723/jumdc.v11i1.306

This is an Open Access article distributed under the terms of the Creative Commons Attribution License (http://creativecommons.org/licenses/by/4.0), which permits unrestricted use, distribution, and reproduction in any medium, provided the original work is properly cited. 


\section{INTRODUCTION:}

Midline abdominal incisions cater a number of benefits for the surgeon but one draw-back is significant pain in post-operative phase ${ }^{[1]}$. This pain is one of the most important factors in limiting early mobilization of patient, increasing requirement for post-operative analgesics and respiratory tract complications, eventually decreasing the rate of recovery ${ }^{[1]}$.

If post-operative pain is not adequately controlled it may lead to various unwanted outcomes that not only prove problematic for the patient but also increase length of hospital stay of the patient putting additional but avoidable burden on hospital resources ${ }^{[2]}$.

Various methods of post-operative pain control are practiced worldwide ${ }^{[3]}$. One of the newer methods is injecting a long acting local anesthetic like bupivacaine in the skin around the surgical incision ${ }^{[2]}$. This blocks pain signals originating at the cut edges of the skin from reaching higher centers thereby reducing the morbidity caused by pain. This injection may be repeated at appropriate intervals with comparatively low chance of complications ${ }^{[4]}$. This technique is usually coupled with continuous baseline analgesia provided by intravenous/ intramuscular injection of either an NSAID (e.g. Ketorolac, Diclofenac) or an opioid (Nalbuphine, Morphine) ${ }^{[5]}$. Combination of a centrally acting analgesic and peripheral blockage of pain sensations is theoretically more effective than individual use of these two modalities.

This method has been used in various different specialties like general surgery, ${ }^{3,6}$ orthopedics, ${ }^{4,5}$ gynecology ${ }^{2}$ and interventional cardiology ${ }^{7}$ with variable response. Most of the previous studies have found it to be an effective means of reducing post-operative pain especially in the first few hours after surgery, better than intravenous opioid analgesia alone. According to Monsef, et $\mathrm{al}^{[4]}$ these effects are most pronounced at 2 and 4 hours interval after bupivacaine infusion, the effects gradually receding and becoming statistically insignificant from 6 hours onwards. These differences resulted in early mobilization, reduced requirement of post-operative analgesics, reduced overall morbidity and early discharge of the patient ${ }^{[2,4,6]}$. Patients receiving local
Corresponding Author:

Dr. Farhad Alam,

Senior Registrar, Children Hospital Faisalabad.

I Email: mudaser4farhad@yahoo.com

infiltration of bupivacaine had pain score of $3.33 \pm 1.65$ at closure as compared to control $5.62 \pm 1.150$ ( $p$-value <0.001). However, other researchers differ from these findings, stating that there is no appreciable advantage of periincisional bupivacaine infiltration. These studies suggested that the difference in pain scores in patients with and without infiltration of bupivacaine is negligible and not statistically significant ${ }^{[8]}$.

The aim of this study was to assess pain scores in early post-operative phase of patients undergoing exploratory laparotomy using this technique for analgesia, to evaluate the efficacy of this technique, and if it proves beneficial, to establish this technique in future practice.

\section{METHODOLOGY:}

This randomized controlled trial study was conducted at surgical department of Allied hospital Faisalabad from June 2017 to December 2017. The study has been approved by the Ethical review committee of Punjab Medical College Faisalabad. It included 80 patients which were divided into two equal groups by using random tables. Patients between 25 to 65 years of age, from both genders and undergoing laparotomy through midline abdominal incision for any indication were included in this trial while patients with any trauma to anterior abdominal wall, having neurological deficit due to spinal cord trauma, undergoing second-look laparotomy, patients with any pre-operative infective skin/ subcutaneous lesion at the site of incision, patients with disturbed renal function or gastric ulcer contraindicating use of NSAIDs i.e. InjToradol (Ketorolac), were excluded from the study.

After the approval of this study from hospital ethical review committee, all the patients admitted in our unit undergoing exploratory laparotomy for elective or emergency indications were included in the study.

Each participant of the study was informed in 
detail regarding the procedure and an informed consent (written) was taken. Contact details including address and phone number were taken from each patient and recorded on individual patient's record pro-forma for the purpose of documentation.

Participants included in this study were assigned to two groups using random number tables.

In post-operative period, patients of both groups were given treatment as per requirement of their respective diseases. They received a baseline analgesia using Inj Toradol (ketorolac) $30 \mathrm{mg} / 1 \mathrm{ml}$ intravenously every 8 hours, first dose given during the surgery. The study group was additionally given $10 \mathrm{ml}$ Inj bupivacaine $\mathrm{HCl} 0.5 \%$ diluted with $10 \mathrm{ml}$ saline injected into the subcutaneous plane around the incision immediately after the closure of skin and time was noted. No further difference in the treatment of patients of both groups required for the purpose of this study.

The patients in both groups were compared for the degree of pain experienced by them in early post-operative period. This information was collected using Numeric pain scale, 10 being worst pain and 1 meaning least appreciable pain. These assessments were done 2 and 4 hrs. after surgery.

All the data was collected with the help of a questionnaire.

The data were analyzed using SPSS version 18 . For quantitative variables like age, BMI and Numeric pain scores after $4 \mathrm{hrs}$, mean and standard deviation (S.D) was calculated. For qualitative variables like gender, diagnosis leading to laparotomy and the urgency of procedure, frequency and percentages were calculated. Mean pain score for both groups was compared by using independent sample t-test and P-value equal to or less than 0.05 was considered significant. Stratification done for result modifying factors like age, gender, BMI, indications for laparotomy and urgency of procedure and then independent t-test was applied.

\section{RESULTS:}

Total 80 patients who fulfilled the inclusion and exclusion criteria were divided into two groups with 40 patients each and the mean pain scores was compared in early post-operative period between patients given local infiltration of injection bupivacaine and patients without infiltration at surgical incision site of patients undergoing laparotomy.

Age distribution of the patients revealed that $52.5 \%(n=21)$ in study and $57.5 \%(n=23)$ in control group were between $25-40$ years of age whereas $47.5 \%(n=19)$ in study and $42.5 \%(n=23)$ in control group were between 41-65 years of age. Mean \pm SD was calculated as $39.43 \pm 8.63$ years in study and $38.93 \pm 8.51$ years in control group.

Gender distribution manifest as $70 \%(n=28)$ in study and $75 \%(n=30)$ in control group were male whereas $30 \%(n=12)$ in study and $25 \%$ $(n=10)$ in control group were females.

Mean BMI of the patients was recorded as $31.24 \pm 4.74$ in study and $32.41 \pm 3.67$ in control group. (Table-I)

Diagnosis leading to laparotomy categorized as $47.5 \%(n=19)$ in study and $55 \%(n=22)$ in control group had abdominal trauma. $30 \%(n=12)$ in study and $25 \%(n=10)$ in control group had small intestinal perforation whereas $22.5 \%(n=9)$ in study and $20 \%(n=8)$ in control group had abdominal infection.

Urgency of procedure was recorded in $85 \%$ $(n=34)$ in study and $80 \%(n=32)$ in control group whereas $15 \%(n=6)$ in study and $20 \%$ $(n=8)$ in control group had no urgency of procedure (Table-II).

Comparison of pain score were $3.0 \pm 0.75$ in study and $5.2 \pm 0.72$ in control group with $p$ value $=0.0001$ which exhibit significant difference (Table-III).

Data stratification for age, gender, BMI, indications for laparotomy and urgency of procedure was done before applying independent sample t-test. P-value $\leq 0.05$ was considered as significant (Table- IV-VI). 
Table-I: Descriptive Information of Patients.

\begin{tabular}{|c|c|c|c|c|}
\hline \multirow{2}{*}{ Age(In years) } & \multicolumn{2}{|c|}{ Study Group(40) } & \multicolumn{2}{|c|}{ Control Group(40) } \\
\hline & Patients \# & $\%$ & Patients \# & $\%$ \\
\hline $25-40$ & 21 & 52.5 & 23 & 57.5 \\
\hline $41-65$ & 19 & 47.5 & 17 & 42.5 \\
\hline \multicolumn{5}{|l|}{ Gender } \\
\hline Male & 28 & 70 & 30 & \\
\hline Female & 12 & 30 & 10 & 5 \\
\hline Total & 40 & 100 & 40 & 00 \\
\hline Mean土SD & \multicolumn{2}{|c|}{$39.43 \pm 8.63$} & \multicolumn{2}{|c|}{$38.93 \pm 8.51$} \\
\hline \multirow{3}{*}{ BMI } & \multicolumn{2}{|c|}{ Study Group $(n=40)$} & \multicolumn{2}{|c|}{ Control Group $(n=40)$} \\
\hline & Mean & SD & Mean & SD \\
\hline & 31.24 & 4.74 & 32.41 & 3.67 \\
\hline
\end{tabular}

Table-II: Diagnosis Leading to Laparotomy and Urgency of Procedure $(n=80)$.

\begin{tabular}{|c|c|c|c|c|}
\hline \multirow{2}{*}{ Diagnosis leading to laparotomy } & \multicolumn{2}{|c|}{ Study Group } & \multicolumn{2}{c|}{ Control Group } \\
\cline { 2 - 5 } & No. of patients & $\%$ & No. of patients & $\%$ \\
\hline Abdominal trauma & 19 & 47.5 & 22 & 55 \\
\hline Small Iintestinal perforation & 12 & 30 & 10 & 25 \\
\hline Abdominal infection & 9 & 22.5 & 8 & 20 \\
\hline \multicolumn{2}{|c|}{ Urgency of Procedure } & 85 & 32 & 80 \\
\hline Yes & 34 & 15 & 8 & 20 \\
\hline No & 6 & $\mathbf{1 0 0}$ & $\mathbf{4 0}$ & $\mathbf{1 0 0}$ \\
\hline
\end{tabular}

Table-III: Comparison of Mean pain Score at 4-hours after Surgery $(n=80)$.

\begin{tabular}{|c|c|c|c|c|}
\hline \multirow{3}{*}{ Pain score } & \multicolumn{2}{|c|}{ Study Group } & \multicolumn{2}{c|}{ Control Group } \\
\cline { 2 - 5 } & Mean & SD & Mean & SD \\
\cline { 2 - 5 } & 3.0 & 0.75 & 5.2 & 0.72 \\
\hline
\end{tabular}

P-value: 0.0001 
Table-IV: Stratification for Age \& Gender of the Patients $(n=80)$.

\begin{tabular}{|c|c|c|c|c|c|}
\hline \multirow{2}{*}{ Age (In Years) } & \multicolumn{2}{|c|}{ Study Group (n=40) } & \multicolumn{2}{c|}{ Control Group (n=40) } & \multirow{2}{*}{ P-value } \\
\cline { 2 - 5 } & Mean & SD & Mean & SD & 0.0001 \\
\hline $25-40$ & 3.10 & 0.77 & 5.17 & 0.78 & 0.001 \\
\hline $41-65$ & 2.89 & 0.74 & 5.24 & 0.66 & 0.0001 \\
\hline Gender & 2.96 & 0.88 & 5.20 & 0.71 & 0.001 \\
\hline Male & 3.08 & 0.29 & 5.20 & 0.79 & \\
\hline Female &
\end{tabular}

Table-V: Stratification for BMI of the Patients \& Urgency of Procedure $(n=80)$.

\begin{tabular}{|c|c|c|c|c|c|}
\hline \multirow{2}{*}{ BMI } & \multicolumn{2}{|c|}{ Study Group (n=40) } & \multicolumn{2}{c|}{ Control Group (n=40) } & \multirow{2}{*}{ P-value } \\
\cline { 2 - 5 } & Mean & SD & Mean & SD & 0.0001 \\
\hline$\leq 30$ & 3.14 & 0.73 & 5.10 & 0.72 & 0.001 \\
\hline$>30$ & 3.04 & 0.76 & 5.14 & 0.70 & 0.0001 \\
\hline \multicolumn{7}{|c|}{ Urgency of procedure } \\
\hline Yes & 3.18 & 0.69 & 5.14 & 0.68 & 0.0001 \\
\hline No & 3.09 & 0.66 & 5.05 & 0.67 & 0.000 \\
\hline
\end{tabular}

Table-VI: Stratification for Diagnosis Leading to Laparotomy $(n=80)$.

\begin{tabular}{|c|c|c|c|c|c|}
\hline \multirow{2}{*}{$\begin{array}{c}\text { Diagnosis } \\
\text { leading to } \\
\text { laparotomy }\end{array}$} & \multicolumn{2}{|c|}{ Study Group (n=40) } & \multicolumn{2}{c|}{ Control Group (n=40) } & \multirow{2}{*}{ P-value } \\
\cline { 2 - 5 } & Mean & SD & Mean & SD & 0.0001 \\
\hline Abdominal trauma & 3.21 & 0.71 & 5.10 & 0.74 & 0.0001 \\
\hline $\begin{array}{c}\text { Small } \\
\text { Intestinal } \\
\text { Perforation }\end{array}$ & 2.92 & 0.77 & 5.13 & 0.71 & 0.0001 \\
\hline $\begin{array}{c}\text { Abdominal } \\
\text { infection }\end{array}$ & 3.11 & 0.76 & 5.14 & 0.67 & \\
\hline
\end{tabular}

\section{DISCUSSION:}

Intolerable morbidity occurs after major thoracic, orthopedic or abdominal surgeries due to post-operative pain. Inadequately controlled pain leads to patient displeasure and major morbidities like post-operative pulmonary dysfunction and cardiac ischemic changes. Various techniques are presently used to treat this pain and opioids are the most regularly used medications by parenteral route.

We planned this study to assess pain scores in early post-operative phase of patients undergoing exploratory laparotomy using this technique for analgesia. We intended to evaluate the efficacy of this technique, and if it proves beneficial, to establish this technique in our practice. 
We compared our results with a previous study ${ }^{[4]}$ receiving local infiltration of bupivacaine had pain score of $3.33+1.65$ at closure as compared to control $5.62+1.150$ (P-value $<0.001$ ).

The advantage of local wound infiltration was assessed with regards to diminished postoperative narcotics usage, declined VAS score and timely patient mobilization. Surprisingly only once intra-operative local wound infiltration of bupivacaine extend the time to first analgesic dose, lower the VAS score at 4th post-operative hour and diminished the first post-operative day analgesics utilization. The number of patients not in need of analgesics also increased. The results were predominantly notable during the first 24 hours postoperatively but diminished subsequently. During the succeeding time span, the constancy of analgesics usage remained the same as in the control group.

On the other hand, a study by Hariharan, et al ${ }^{[9]}$ has proclaimed that local wound infiltration either before or even after surgical incision did not markedly reduce the post-operative pain after total abdominal hysterectomy. But uninterrupted local wound infiltration was outmatched, as compared to ones with peroperative wound infiltration as well as postoperative opioids for sustained analgesia. However, its functionality for the post-operative pain also determined by the type of surgery.

A randomized double blind study by Tauzin-Fin et $\mathrm{al}^{[10]}$ reported a cutback in overall tramadol utilization to $221 \pm 64.1 \mathrm{mg}$ in group receiving intravenous magnesium sulfate along with ropivacaine local wound infiltration and even to $134 \pm 74.9 \mathrm{mg}$ in other group receiving magnesium added ropivacaine locally in wound after radical retropubic prostatectomy.

On the contrary, in another study by Berthon et al $^{[11]}$, it was noticed that local wound infiltration with anesthetic agent was not advantageous in laparoscopic prostatectomy and recommended that it should not be consumed on regular basis. We can say the postoperative pain after minimal invasive surgeries is generally trivial to start with.

In a comparably similar randomized double blind study by Updike and colleagues ${ }^{[12]}$ on 68 patients, they used placebo for control group. At incision site just before total abdominal hysterectomy, they infiltrated the operation site either with $30 \mathrm{ml}$ of ropivacaine or placebo. They established similar outcome in both groups in relation to pain score and narcotic usage frequency at any time during post-operative time span.

However, contemporary studies provided evidence for better pain control and diminished opioid consumption by use of uninterrupted wound infiltration. Other beneficial consequences included lesser duration of ileus and shorter length of hospital stay with significant reduction in per patient cost ${ }^{[13]}$.

Local analgesic infiltration of surgical site is oldest and most commonly performed method however now a modality of ultrasound guided TAP block proved a better analgesic quality as compared to LAI for reducing postoperative pain ${ }^{[14,15]}$. A study by Ali, et al showed significant reduction in mean pain score at 12 hours postoperatively and less mean opiate requirement in patient with TAP block as compared to LAI with $P$-value $<0.05^{[16]}$.

Similar beneficial results of TAP block shown by Khan, et al for open appendectomy and inguinal hernia repair, by Sivapurapu et al for lower abdominal gynecological surgeries and by Patersen et al for laparoscopic cholecystectomy [19].

The findings of our study revealed that "Patients infiltrated with injection bupivacaine around surgical incision experience less pain in early post-operative period in comparison to patients getting only intravenous analgesics."

\section{CONCLUSION:}

We concluded that there is a significant decrease in pain score in patients infiltrated with injection bupivacaine around surgical incision in early post-operative period as compared to those getting only intravenous analgesics.

\section{CONFLICT OF INTEREST:}

All authors disclose no conflict of interest.

\section{Grant Support \& Financial Disclosures: None.}




\section{REFERENCES:}

1. Hollinsky C. Individualized or standard approach to the abdomen : Currently available data. Chirurg. 2016;87(9):731-6.

2. Ravndal C, Vandrevala T. Preemptive Local Anesthetic in Gynecologic Laparoscopy and Postoperative Movement- Evoked Pain: A Randomized Trial. J Minim Invasive Gynecol. 2016;23(5):775-80.

3. Lai HC, Hsieh CB, Wong CS, Yeh CC, Wu ZF. Preincisional and postoperative epidural morphine, ropivacaine, ketamine, and naloxone treatment for postoperative pain management in upper abdominal surgery. ActaAnaesthesiol Taiwan.2016;54(3):8892.

4. Monsef $A E$, Hamedsedek AE, Kassab FA. Study of the ffectiveness of of local anesthetic wound infiltration in post cesarean section pain relief. AAMJ.2015; 13(1):152-62.

5. Yan $H$, Cang J, Xue $Z$, Lu J, Wang $H$. Comparison of local infiltration and epidural analgesia for postoperative pain control in total knee arthroplasty and total hip arthroplasty: A systematic review and meta-analysis. Bosn J Basic Med Sci. 2016;16(4):239-46.

6. Qureshi RM, Khan FA. Effects of bupivacaine infiltration on postoperative tramadol consumption in elective day care unilateral inguinal hernia repair. J Pak Med Assoc. 2016;66(3):256-9.

7. Palma A, Viegas J, Manlhiot C, McCrindle B, Benson L. Use of local anesthetic (0.25\% bupivacaine) for pain control after pediatric cardiac catheterization: A randomized controlled trial. Catheter Cardiovascinterv. 2016;87(2):318-23.

8. Hinarejos $P$, Capurro B, Santiveri $X$, Ortiz $P$, Leal J, Pelfort X. Local infiltration analgesia adds no clinical benefit in pain control to peripheral nerve blocks after total knee arthroplasty. Knee Surg Sports Traumatol Arthrosc. 2016;24(10):3299-305.

9. Hariharan S, Moseley H, Kumar A, Raju S. The effect of preemptive analgesia in postoperative pain relief - a prospective double-blind randomized study. Pain Med 2009;10:49-59.

10. Tauzin-Fin P, Sesay M, Svartz L. Wound infiltration with magnesium sulphate and ropivacaine mixture reduces postoperative tramadol requirements after radical prostatectomy. Acta Anaesthesiol Scand 2009;53:464-9.

11. Berthon N, Plainard X, Cathelineau X. Effect of wound infiltration of ropivacaine in postoperative pain after extraperitoneal laparoscopic radical prostatectomy. ProgUrol2010;20(6):435-9.

12. Updike GM, Manolistas TP, Cohn DE. Preemptive analgesia in gynecologic surgical procedures: preoperative wound infiltration with ropivacaine in patients who undergo laparotomy through a midline vertical incision. Am J Obstet Gynecol 2003;188:901-5.

13. Gomez Rios MA, Vazquez Barreiro L, Nieto Serradilla L. Efficacy of a continuous infusion of local anesthetic into the surgical wound for pain relief after abdominal hysterectomy. Rev EspAnestesiolReanim 2009;56(7):417-24.

14. Ventham NT,Hughes $M, O^{`}$ Neill $S$, Johns $\mathrm{N}$, Brady PR, Wigmore SJ.Systematic review and meta analysis of continuous local anesthetic wound infilteration versus epidural analgesia for postoperative pain following abdominal surgery. $\mathrm{Br}]$ Anaesth 2013;100(10):1280-9.

15. Ismail S, Khan MR,Urooj S.Use of tranversus abdominis plane block as an anesthetic technique in a high risk patient for abdominal wall surgery.J Anaesthesiol Clin Pharmacol 2013;29(4):581-2.

16. Ali L,Waseem M,Iqbal A.Comparison of analgesic efficacy of Transversus abdominis plane block with conventional local anesthetic wound infilteration.Pak Armed Forces Med J 2018;68(5);1106-10.

17. SM Khan,S Nawaz,MB Delvi,T Alzahrani. Intraoperative ultrasound guided transversus abdominis plane block in lower abdominal surgery. Int J Perioerative Ultrasound Appl Technol 2012;1(1):1-4.

18. V Sivapurapu,A Vasudevan,S Gupta,AS Badhe.comparison of analgesic efficacy of tranversus abdominis plane block with direct infilteration of local anesthetic into surgical incision in lower abdominal gynecological surgeries.J Anaesthesiol Clin Pharma 2013;29(1):71-5. 
19. PL Patersen, P Stjernholm, VB Kristiansen, $H$ Torup, EG Hansen Au, Mitchell et al. The beneficial effect of transversus abdominis plane block after laparoscopic cholecystectomy in day case surgery. J Soc Ambulatory Anesthesiology 2012;(115): 527-33.

\section{Authors' Contribution:}

Mudassar Jabeen: Write up, formatting, references, proof reading.

Fawad Zafar: Data collection, preparations of results, study design.
Sumara Tabassam: Data analysis, review of literature.

Farhad Alam: Literature search review, proof reading.

Muhammad Sohail: Critical review of manuscript and clinical support.

Failures are often the results of timidity and fears; disappointments are the results of bashfulness; hours of leisure pass away like summer-clouds, therefore, do not waste opportunity of doing good Hazrat Ali (Karmulha Wajhay) 